\title{
The Effect of Sea Level Rise on Egyptian Economy
}

\author{
Ahmed Dawood \\ Lecturer of Navigation in the Department of Nautical Studies, College of Maritime Transport \& Technology, Arab Academy for \\ Science, Technology and Maritime Transportation, Alexandria 21937, Egypt
}

\begin{abstract}
The vulnerability of Egypt to potential impacts of sea level rise has been considered. It was recognized that many locations in Egyptian Coast, on Mediterranean Sea (Mersa Matruh, Alexandria and Port Said) and on Red Sea (Hurghada), are highly vulnerable to the potential impacts of sea level rise, salt water intrusion and increase of frequency and severity of storm surges. The aim of this study is to investigate the monthly average and the variations of sea level and meteorological conditions along the Egyptian Mediterranean and north Red Sea coasts. Monthly mean cycles and correlation coefficients between MSL (Mean Sea Level) and different meteorological parameters were also calculated. The analyzed data was from 2007 to 2009 covering 3 years of hourly recorded sea level and meteorological parameters were used except for Hurghada sea level was for 2007 and 2008 . Sea level harmonic analyses were done by using TOGA (Tropical Ocean and Global Atmosphere) software. Sea level variations were also computed, and it was 20.1, 20, 0.1 and $55.3 \mathrm{~cm}$ in Alexandria, Port Said, Mersa Matruh and Hurghada respectively. The annual of the tidal constituents were computed to determine the MSL. Surge calculations were done by using TOGA software and eliminating the predicted tide from the observed sea level. The average calculated surge was also analyzed that the highest surge happened during summer and the lowest during winter in Alexandria and Port Said, while the highest surge was during winter and the lowest during summer in Hurghada. The surge variation was very weak in Mersa Matruh. The result of multiple regression analysis is a statistically significant relationship between the variables at the $99 \%$ confidence level.
\end{abstract}

Key words: Surge, harmonic, tide, correlation, temperature.

\section{Introduction}

MSL (Mean Sea Level) is the measure of the average height of the ocean's surface (such as the halfway point between the mean high tide and the mean low tide), used as a standard in reckoning land elevation.

Higher global ambient temperatures, thermal expansion of ocean waters, subsidence of coastal lands and increased melting of sea ice are just some of the factors that can contribute to sea level rise. Some estimates predict that sea level rise of approximately $50 \mathrm{~cm}$ could result from these factors. The effect on vulnerable coastlines, coastal communities and coastal infrastructure would then range from serious to catastrophic. The social, economic, cultural and ecological foundations of human life in these areas could be seriously affected [1].

Currently, sea level change is of considerable

Corresponding author: Ahmed Dawood, master, research field: maritime safety and security. interest because of its potential impact on human populations living in coastal regions and on islands. This study focuses on regional sea level variations and the effect of meteorological elements on it over time.

Any rise in sea level will have adverse impacts (e.g. coastal erosion and flooding) which depend on the time scale and the magnitude of the rise, as well as the associated human response.

A rise in sea level may be due to a multiple factors at various time scales. Not only atmospheric storms or river flooding in estuaries [2], but also the sinking or rising of land (and similar non-climate related changes) is linked to isostasy or the construction of buildings.

Sea level changes are a subject of many interdisciplinary investigations such as a greenhouse effect and the global temperature changes. A rise in sea level will generate a need for a coastline protection and possible intrusion of seawater into freshwater areas in the future [3]. All these suggest the necessity of a careful study of mean sea level changes. 
A surge is an offshore rise of water associated with a high and low pressure weather system. Surge is caused primarily by winds that push the ocean's surface. The wind causes the water to move higher or lower than the ordinary sea level. Pressure at the center of a weather system also has a small secondary effect, as well as the bathymetry of the body of water. It is the combined effect of atmospheric pressure and persistent wind over the water body which is the most common cause of surge. The term "storm surge" in casual (non-scientific) use is storm tide; that is, it refers to the rise of water associated with the storm, plus tide, wave run-up and freshwater flooding. When referring to storm surge height, it is important to clarify the usage, as well as the reference point. NHC (National Hurricane Center) tropical storm reports reference storm surge as water height above predicted astronomical tide level and storm tide as water height above NGVD-29 (National Geodetic Vertical Datum-29).

It represents an ocean reaction to the large-scale impact of atmospheric pressure and wind. Irregular currents and level variations related to movement of pressure disturbances over sea-shelf might cause floods on flat coasts sometimes leading to catastrophic consequences. [4]

The tidal harmonic analysis technique is the main tool in analyzing of tidal data which collected from hourly tidal observations by tide gauge. From this technique, the amplitudes and phase angle of the tidal constituents and mean sea level at a specific location can be determined, which used in prediction of tide for the same locations.

The effect of wind on sea level is very variable and depends largely on the topography of the coastline [5]. The direct effect of the tangential stress of the wind on the sea surface brings about arising or a lowering of the sea level.

A strong wind blowing straight on shore will pile up the water and cause the raising up in sea level, while wind blowing off the land will have the reverse effect.
Owing to the influence of the earth's rotation, the moving water masses are deflected to the right in the northern hemisphere and to the left in the southern hemisphere. When these water masses reach the coastline, the sea level increases rapidly, since the water is piled up, resulting thus in a positive storm surge or set-up. If the net water transport is directed away from the coast, the result is lowering in the sea level, which is described as a negative storm surge or set-up the most pronounced storm surges generally arise in relatively shallow sea regions bordering the oceans and in shallow marginal [6].

\section{Research Problem}

The objective of this paper is to identify and assess some of the main vulnerable areas to sea level rise in Egyptian Governorates on Mediterranean and Red Seas. The main objective is to identify vulnerabilities to sea level rise and to assess adaptation measures and point out the urgent need to build up institutional and human capacities to approach the problem and to identify gaps, points of strength and weakness, options of adaptation and needs for sustainable development.

\subsection{Research Questions}

What is the effect of Sea Level Rise on the Egyptian Economy?

When does the effect of Sea Level Rise start to arise?

\section{Research Methodology}

This research is a descriptive research to investigate the monthly average and the variations of sea level and meteorological conditions along the Egyptian Mediterranean and north Red Sea coasts and is using the following procedures:

(a) Literature review;

(b) Analysis of Sea Level Data during the period (2007 to 2009) by using TOGA (Tropical Ocean and Global Atmosphere) and STATGRAGH softwares;

(c) Suggestions based on the statistical results and previous studies for solving the research problem. 


\section{Literature Review}

Meligy, M. M. [7] studied wind waves and surge and applied these methods along the Egyptian coast of the Mediterranean Sea and studied the effect of the depression movements on the wind waves along the Egyptian coast of the Mediterranean Sea at Alexandria, Abu Qir and Ras Elbar during the period 1992 to 1995. The storm surge at Alexandria from observed sea level during the period 1995 to 1998 was calculated. The mean sea level was also found $51 \mathrm{~cm}$.

Dawod, G. et al. [8] studied the mean sea level along the Egyptian coast of the Mediterranean Sea with observations at Alexandria during the period (2001-2003) and collecting data from 1944. Also at Portsaid, during the periods of 1990-1991, 1997-2003 and 1926-1965, the mean sea level was found $51 \mathrm{~cm}$.

\section{Analysis of Sea Level Data during the Period (2007 to 2009)}

\subsection{Tide Interaction}

The difference between actual sea level (with its seasonal, annual and inter-annual components excluded) and the sum of surge and tidal level components is a commonly accepted measure of this interaction [4].

\subsection{Surge Heights Estimation}

The surge at any location, derived from the observation of the sea level may therefore be regarded as consisting of a part generated by wind stress acting tangentially over the sea surface, and another part generated by barometric pressure [9]. The meteorological effects on sea level are superimposed on the normal astronomical tide. To compute the storm surge at a coastal location from a sea level recorded there, the main problem is the elimination of the tide. This can be done by various methods [9].

\subsection{Elimination of the Predicted Astronomical Tide Method}

In this method, it is desired to eliminate the astronomical sea level elevation from the observed one by subtraction of the predicted tide from the recorded heights to get the hourly surge heights.

In order to be able to predict the tide at any place, it is necessary as a first step to determine the harmonic components and their respective phase angles, and then it becomes a process of addition and multiplication to predict the tide.

\subsection{Sea Level Harmonic Analysis}

The tide is caused by the attraction of the sun and the moon on the oceans and the rotation of the earth. The precise pattern at any particular spot along the coast depends strongly on the shape of the coastline and on the profile of the seafloor nearby. Furthermore, in shallow seas, bays and estuaries co-oscillating tides and resonance contribute to a large amount to the final shape of the tides. The tides at any specific location are essentially impossible to be calculated theoretically even though the generating gravitational forces are very precisely known.

Coastal seas frequencies occur in shallow water. The shallow water constituents are called compound tides and over tides. They are mainly results of the nonlinear dynamic processes which are present in the physics governing the motion of water, namely:

- Dependence of the celerity of a tidal wave on the actual water depth;

- Nonlinear bottom friction;

- Advection of momentum.

From the monthly analysis result, author can conclude that: the maximum values in August are 61.6 and 70 $\mathrm{cm}$, while the minimum value in April is $40.6 \mathrm{~cm}$ and in February $50 \mathrm{~cm}$. And the differences between the maximum and the minimum values are 20.1 and 20 $\mathrm{cm}$ in Alexandria and Port Said, respectively.

The minimum value in Mersa Matruh was $32.7 \mathrm{~cm}$, while the maximum was $32.8 \mathrm{~cm}$, and the difference between the maximum and the minimum values was $0.1 \mathrm{~cm}$. Therefore, there is a very small change in Mersa Matruh's sea level during the year. 
The maximum value in Hurghada in December was $140.9 \mathrm{~cm}$, while the minimum in August was $85.6 \mathrm{~cm}$, and the difference between the maximum and the minimum values was $55.3 \mathrm{~cm}$. Therefore, there is a large change in Hurghada's sea level during the year.

Tables 1-4 represent the annual tidal constituents using harmonic analysis in the four stations.

The difference between the maximum and the minimum values were 2.9, 0.04, 0.002 and $4.4 \mathrm{~cm}$ for Alexandria, Port Said, Mersa Matruh and Hurghada, respectively, so the highest change in sea level happened in Hurghada and the lowest in Mersa Matruh.

The MSL in Alexandria is $51 \mathrm{~cm}$, and this agreed with results got by Meligy, M. M. [7] and Dawod, G. et al. [8] and bigger than the results got by Rady, A. [5] and El Din, S. S. et al. [10].

\subsection{Surge Calculation}

The result of the elimination of the predicted tide from the observed sea level is the calculated surge.
Elimination of the predicted tide from the observed sea level made by using sea level data processing on the TOGA software, for Alexandria, Port Said, Mersa Matruh and Hurghada during the period of study.

Tables 5-8 are the monthly average surge in Alexandria, Port Said, Mersa Matruh and Hurghada respectively, during the period of the study.

The maximum surge values happened in July $34.1 \mathrm{~cm}$, August $11.5 \mathrm{~cm}$, April $0.36 \mathrm{~cm}$ and February $14.6 \mathrm{~cm}$, and the minimum surge values happened in February $9.29 \mathrm{~cm}$, February $-10 \mathrm{~cm}$, June $-0.43 \mathrm{~cm}$ and August $-15.4 \mathrm{~cm}$ in Alexandria, Port Said, Mersa Matruh and Hurghada respectively.

The differences between the maximum and the minimum values are Alexandria $24.8 \mathrm{~cm}$, Port Said $21.5 \mathrm{~cm}$, Mersa Matruh $0.8 \mathrm{~cm}$ and Hurghada $30 \mathrm{~cm}$.

Table 9 illustrates the yearly average surge in the area of study that Alexandria has maximum value $21.4 \mathrm{~cm}$ while Mersa Matruh has the minimum value $-0.08 \mathrm{~cm}$.

Table 1 The annual tidal constituents using harmonic analysis in Alexandria during the period from 2007 to 2009 (AL: amplitude) (GL: phase angle).

\begin{tabular}{|c|c|c|c|c|}
\hline & & 2007 & 2008 & 2009 \\
\hline \multirow{2}{*}{ SO } & $\mathrm{Al}$ & 52.903 & 50.059 & 49.882 \\
\hline & GL & 0 & 0 & 0 \\
\hline \multirow{2}{*}{ MM } & $\mathrm{Al}$ & 3.6456 & 4.1908 & 2.9625 \\
\hline & GL & 190.56 & 193.38 & 184.59 \\
\hline \multirow{2}{*}{ MSF } & $\mathrm{Al}$ & 2.2734 & 3.2418 & 3.2219 \\
\hline & GL & 166.08 & 149.96 & 174.3 \\
\hline \multirow{2}{*}{$\mathrm{O} 1$} & $\mathrm{Al}$ & 2.1076 & 0.8098 & 1.1077 \\
\hline & GL & 212.83 & 196.59 & 167.34 \\
\hline \multirow{2}{*}{ M1 } & $\mathrm{Al}$ & 0.7591 & 0.5075 & 0.5329 \\
\hline & GL & 221.83 & 233.89 & 153.73 \\
\hline \multirow{2}{*}{ K1 } & $\mathrm{Al}$ & 1.7676 & 1.8301 & 1.4123 \\
\hline & GL & 224.8 & 201.58 & 153.49 \\
\hline \multirow{2}{*}{ MU2 } & $\mathrm{Al}$ & 0.9888 & 0.8136 & 0.6085 \\
\hline & GL & 213.51 & 203.81 & 166.55 \\
\hline \multirow{2}{*}{ N2 } & $\mathrm{Al}$ & 0.8364 & 0.9389 & 0.7786 \\
\hline & GL & 203.22 & 149.58 & 215.18 \\
\hline \multirow{2}{*}{ M2 } & $\mathrm{Al}$ & 2.7248 & 3.2938 & 1.0238 \\
\hline & GL & 278.49 & 195.38 & 141.26 \\
\hline \multirow{2}{*}{ L2 } & $\mathrm{Al}$ & 1.1072 & 0.9883 & 1.0983 \\
\hline & GL & 188.6 & 223.02 & 166.8 \\
\hline \multirow{2}{*}{$\mathrm{S} 2$} & $\mathrm{Al}$ & 2.205 & 2.0567 & 1.0722 \\
\hline & GL & 292.31 & 317.98 & 217.49 \\
\hline
\end{tabular}


Table 1 continued

\begin{tabular}{lllll}
\hline & & 2007 & 2008 & 2009 \\
\hline \multirow{2}{*}{ SMM } & Al & 1.2971 & 0.6712 & 0.8273 \\
& GL & 292.26 & 222.37 & 86.39 \\
K2 & Al & 0.5995 & 0.5589 & 0.2937 \\
& GL & 294.3 & 319.38 & 219.07 \\
NU2 & Al & 0.1622 & 0.181 & 0.1528 \\
& GL & 203.87 & 148.94 & 215.58 \\
\hline
\end{tabular}

Table 2 The annual tidal constituents using harmonic analysis in Port Said during the period from 2007 to 2009 (AL: amplitude) (GL: phase angle).

\begin{tabular}{|c|c|c|c|c|}
\hline & & 2007 & 2008 & 2009 \\
\hline \multirow{2}{*}{ SO } & $\mathrm{Al}$ & 62.739 & 62.745 & 62.77 \\
\hline & GL & 360 & 360 & 360 \\
\hline \multirow{2}{*}{ MM } & $\mathrm{Al}$ & 0.0076 & 0.0054 & 0.0168 \\
\hline & GL & 211.01 & 210.31 & 354.92 \\
\hline \multirow{2}{*}{ MSF } & $\mathrm{Al}$ & 0.0011 & 0.0011 & 0.0088 \\
\hline & GL & 44.07 & 218.15 & 190.47 \\
\hline \multirow{2}{*}{$\mathrm{O} 1$} & $\mathrm{Al}$ & 0.1673 & 0.1748 & 0.1871 \\
\hline & GL & 83.73 & 339.48 & 70.71 \\
\hline \multirow{2}{*}{$\mathrm{MF}$} & $\mathrm{Al}$ & 0.004 & 0.0046 & 0.0049 \\
\hline & GL & 307.78 & 14.08 & 202.33 \\
\hline \multirow{2}{*}{ K1 } & $\mathrm{Al}$ & 0.1791 & 0.1871 & 0.1911 \\
\hline & GL & 267.44 & 270.74 & 91.38 \\
\hline \multirow{2}{*}{ MU2 } & $\mathrm{Al}$ & 0.0373 & 0.0381 & 0.0406 \\
\hline & GL & 238.67 & 39.16 & 223.71 \\
\hline \multirow{2}{*}{ N2 } & $\mathrm{Al}$ & 0.2358 & 0.236 & 0.2333 \\
\hline & GL & 237.73 & 225.2 & 232.95 \\
\hline \multirow{2}{*}{ M2 } & $\mathrm{Al}$ & 1.2403 & 1.2312 & 1.218 \\
\hline & GL & 75.57 & 335.57 & 247.24 \\
\hline \multirow{2}{*}{ L2 } & $\mathrm{Al}$ & 0.0334 & 0.0373 & 0.04 \\
\hline & GL & 99.09 & 272.48 & 80.33 \\
\hline \multirow{2}{*}{$\mathrm{S} 2$} & $\mathrm{Al}$ & 0.7011 & 0.7 & 0.7018 \\
\hline & GL & 253.98 & 253.86 & 254.16 \\
\hline \multirow{2}{*}{ 2SM6 } & $\mathrm{Al}$ & 0.0009 & 0.0015 & 0.0025 \\
\hline & GL & 7.19 & 261.55 & 4.48 \\
\hline \multirow{2}{*}{ K2 } & $\mathrm{Al}$ & 0.1475 & 0.1577 & 0.1701 \\
\hline & GL & 61.02 & 67.88 & 69.44 \\
\hline \multirow{2}{*}{ NU2 } & $\mathrm{Al}$ & 0.0426 & 0.043 & 0.0438 \\
\hline & GL & 81.43 & 148.8 & 240 \\
\hline
\end{tabular}

Table 3 The annual tidal constituents using harmonic analysis in Mersa Matruh during the period from 2007 to 2009 (AL: amplitude) (GL: phase angle).

\begin{tabular}{lllll}
\hline & & 2007 & 2008 & 2009 \\
\hline \multirow{2}{*}{ SO } & Al & 32.793 & 32.795 & 32.792 \\
& GL & 360 & 360 & 360 \\
MM & Al & 0.0009 & 0.0023 & 0.0026 \\
& GL & 1.86 & 286.55 & 287.19 \\
MSF & Al & 0.002 & 0.0006 & 0.0015 \\
& GL & 273.26 & 53.76 & 351.34 \\
O1 & Al & 0.0846 & 0.0871 & 0.0954 \\
& GL & 79.9 & 335.39 & 65.3 \\
\hline
\end{tabular}


Table 3 continued

\begin{tabular}{|c|c|c|c|c|}
\hline & & 2007 & 2008 & 2009 \\
\hline \multirow{2}{*}{ MF } & $\mathrm{Al}$ & 0.0006 & 0.0011 & 0.0011 \\
\hline & GL & 114.93 & 180.62 & 183.32 \\
\hline \multirow{2}{*}{ K1 } & $\mathrm{Al}$ & 0.1806 & 0.1844 & 0.1917 \\
\hline & GL & 266.56 & 270.69 & 91.59 \\
\hline \multirow{2}{*}{ MU2 } & $\mathrm{Al}$ & 0.0215 & 0.021 & 0.0225 \\
\hline & GL & 247.93 & 49.89 & 228.13 \\
\hline \multirow{2}{*}{$\mathrm{N} 2$} & $\mathrm{Al}$ & 0.1403 & 0.1355 & 0.1332 \\
\hline & GL & 241.92 & 231.1 & 237.7 \\
\hline \multirow{2}{*}{ M2 } & $\mathrm{Al}$ & 0.7248 & 0.7201 & 0.7138 \\
\hline & GL & 80.87 & 340.2 & 252.39 \\
\hline \multirow{2}{*}{ L2 } & $\mathrm{Al}$ & 0.0172 & 0.0212 & 0.0231 \\
\hline & GL & 99.02 & 277.13 & 88.66 \\
\hline \multirow{2}{*}{$\mathrm{S} 2$} & $\mathrm{Al}$ & 0.401 & 0.3985 & 0.3984 \\
\hline & GL & 258.72 & 258.64 & 258.66 \\
\hline \multirow{2}{*}{ 2SM6 } & $\mathrm{Al}$ & 0.0027 & 0.0028 & 0.0023 \\
\hline & GL & 67.33 & 224.1 & 240.36 \\
\hline \multirow{2}{*}{ K2 } & $\mathrm{Al}$ & 0.0836 & 0.0897 & 0.0984 \\
\hline & GL & 65.72 & 72.15 & 74.43 \\
\hline \multirow{2}{*}{ NU2 } & $\mathrm{Al}$ & 0.0267 & 0.0277 & 0.0279 \\
\hline & $\mathrm{GL}$ & 83.54 & 160.23 & 242.24 \\
\hline
\end{tabular}

Table 4 The annual tidal constituents using harmonic analysis in Hurghada during the period (2007-2008) (AL: amplitude) (GL: phase angle).

\begin{tabular}{|c|c|c|c|}
\hline & & 2007 & 2008 \\
\hline \multirow{2}{*}{$\mathrm{SO}$} & $\mathrm{Al}$ & 105.1667 & 100.732 \\
\hline & GL & 360 & 360 \\
\hline \multirow{2}{*}{ K1 } & $\mathrm{Al}$ & 0.214111 & 0.1958 \\
\hline & GL & 195 & 199 \\
\hline \multirow{2}{*}{ MSF } & $\mathrm{Al}$ & 0.102811 & 0.03266 \\
\hline & GL & 169 & 149 \\
\hline \multirow{2}{*}{$\mathrm{O} 1$} & $\mathrm{Al}$ & 0.101 & 0.0986 \\
\hline & GL & 207 & 206 \\
\hline \multirow{2}{*}{ Q1 } & $\mathrm{Al}$ & 0.019222 & 0.0192 \\
\hline & GL & 202 & 205 \\
\hline \multirow{2}{*}{ SK3 } & $\mathrm{Al}$ & 0.004 & 0.00285 \\
\hline & GL & 177 & 128 \\
\hline \multirow{2}{*}{$\mathrm{N} 2$} & $\mathrm{Al}$ & 0.488667 & 0.5074 \\
\hline & GL & 158 & 162 \\
\hline \multirow{2}{*}{ M2 } & $\mathrm{Al}$ & 2.492667 & 2.4934 \\
\hline & GL & 175 & 174 \\
\hline \multirow{2}{*}{$\mathrm{J} 1$} & $\mathrm{Al}$ & 0.011667 & 0.0074 \\
\hline & GL & 235 & 180 \\
\hline \multirow{2}{*}{$\mathrm{S} 2$} & $\mathrm{Al}$ & 0.401222 & 0.431 \\
\hline & GL & 200 & 206 \\
\hline \multirow{2}{*}{ 2SM6 } & $\mathrm{Al}$ & 0.001722 & 0.00175 \\
\hline & GL & 179 & 219 \\
\hline \multirow{2}{*}{ ETA2 } & $\mathrm{Al}$ & 0.015778 & 0.021 \\
\hline & GL & 170 & 136 \\
\hline \multirow{2}{*}{ MK3 } & $\mathrm{Al}$ & 0.002867 & 0.0024 \\
\hline & GL & 183 & 204 \\
\hline
\end{tabular}


Table 5 The average calculated surge in Alexandria (2007 to 2009).

\begin{tabular}{llll}
\hline & 2007 & 2008 & 2009 \\
\hline January & 20.51 & 19.99 & 10.52 \\
February & 14.31 & 12.60 & 9.29 \\
March & 16.89 & 10.23 & 12.28 \\
April & 15.17 & 12.92 & 17.15 \\
May & 15.03 & 14.24 & 17.44 \\
June & 19.82 & 21.50 & 25.79 \\
July & 34.10 & 25.42 & 24.90 \\
August & 27.25 & 33.68 & 28.13 \\
September & 24.54 & 30.68 & 27.23 \\
October & 29.73 & 31.45 & 26.12 \\
November & 24.62 & 23.34 & 25.38 \\
December & 23.14 & 20.87 & 24.30 \\
\hline
\end{tabular}

Table 6 The average calculated surge in Port Said (2007 to 2009).

\begin{tabular}{llll}
\hline & 2007 & 2008 & 2009 \\
January & -4.46 & -4.91 & -1.45 \\
February & -9.96 & -10.01 & -1.45 \\
March & -9.90 & -9.98 & -1.41 \\
April & -5.38 & -5.014 & 1.20 \\
May & 0.03 & 0.04 & 2.32 \\
June & -0.04 & 0.10 & 2.29 \\
July & 4.44 & 4.94 & 3.33 \\
August & 10 & 10.01 & 11.52 \\
September & 10.04 & 9.94 & 10.39 \\
October & 5.67 & 5.12 & 6.003 \\
November & 0.07 & 0.06 & 2.21 \\
December & -0.01 & -0.026 & -2.32 \\
\hline
\end{tabular}

Table 7 The average calculated surge in Mersa Matruh (2007 to 2009).

\begin{tabular}{llll}
\hline & 2007 & 2008 & 2009 \\
\hline January & -0.22386 & -0.25801 & -0.28302 \\
February & -0.14379 & -0.02404 & -0.01572 \\
March & 0.138889 & 0.157051 & 0.143082 \\
April & -0.02778 & 0.059295 & 0.366352 \\
May & -0.04739 & -0.19231 & -0.04717 \\
June & -0.29739 & -0.29487 & -0.43239 \\
July & -0.11111 & -0.28526 & -0.29088 \\
August & -0.02778 & -0.13141 & -0.16352 \\
September & 0.091503 & 0.145833 & 0.081761 \\
October & 0.132353 & 0.092949 & 0.25 \\
November & -0.0719 & 0.144231 & 0.040881 \\
December & -0.36765 & -0.1875 & -0.26572 \\
\hline
\end{tabular}

Table 8 The average calculated surge in Hurghada (2007-2008).

\begin{tabular}{lll}
\hline & 2007 & 2008 \\
\hline January & 12.358 & 12.1557 \\
February & 14.6296 & 14.6777 \\
March & 13.554 & 13.6053 \\
\hline
\end{tabular}


Table 8 to be continued

\begin{tabular}{lll}
\hline & 2007 & 2008 \\
\hline April & 5.08333 & 5.06918 \\
May & -2.638889 & -2.75 \\
June & -6.441358 & -6.347484 \\
July & -12.61111 & -12.57704 \\
August & -15.30864 & -15.38836 \\
September & -11.67901 & -12.02673 \\
October & -5.479938 & -5.742138 \\
November & 1.75154 & 1.97013 \\
December & 8.50309 & 8.50472 \\
\hline
\end{tabular}

Table 9 The yearly average surge in the area of study.

\begin{tabular}{llll}
\hline & 2007 & 2008 & 2009 \\
\hline Alexandria & 22.0925 & 21.41 & 20.71083 \\
Port Said & 0.041667 & 0.0225 & 2.719417 \\
Mersa Matruh & -0.07966 & -0.0645 & -0.05136 \\
Hurghada & 0.143385 & 0.095915 & N/A \\
\hline
\end{tabular}

5.6 The Effect of the Meteorological Elements on the Sea Level

Figs. 1-4 represent the relation between air temperature, atmospheric pressure, wind speed, mean sea level and surge at the four stations during the period of the study.

\subsection{The Relation between the Meteorological Elements and Sea Level}

Correlation analyses were made to investigate the relation between the meteorological elements and sea level (Tables 10-13).

The Tables 10-13 illustrate that:

(1) Alexandria: there is a very strong (inversely proportional) relation between temperature and pressure and wind speed, while a strong directly proportional relation with mean sea level and surge;

(2) Port Said: there is a very strong (inversely proportional) relation between temperature and pressure, while a strong directly proportional relation with mean sea level and surge;

(3) Mersa Matruh: there is a very strong (inversely proportional) relation between temperature and pressure, and a very weak relation with wind speed, mean sea level and surge;

(4) Hurghada: there is a very strong (inversely proportional) relation between temperature and pressure and surge, and a moderate relation (inversely proportional) with mean sea level.

There is a very strong (inversely proportional) relation between temperature and pressure, and this result is in good agreement with earlier studies in the four stations. 


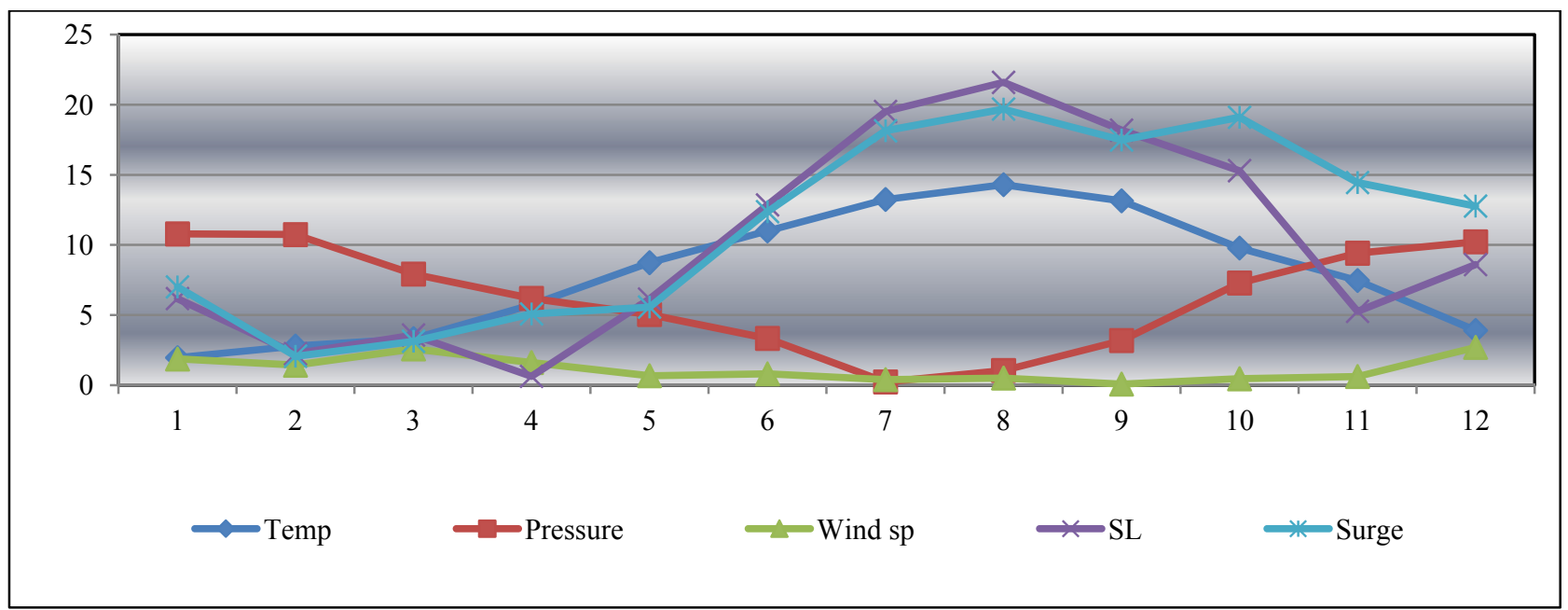

Fig. 1 The relation between air temperature, atmospheric pressure, wind speed, mean sea level and surge at Alexandria during the period of the study [11].

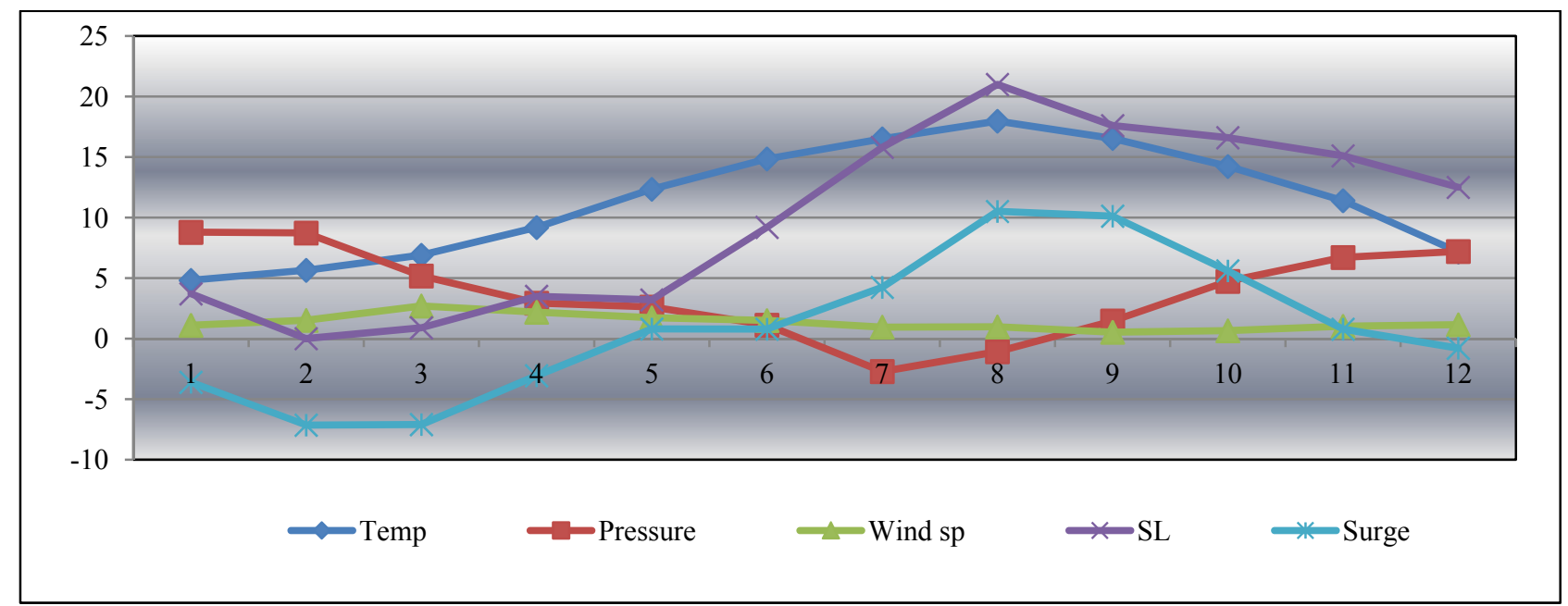

Fig. 2 The relation between air temperature, atmospheric pressure, wind speed, mean sea level and surge at Port Said during the period of the study [11].

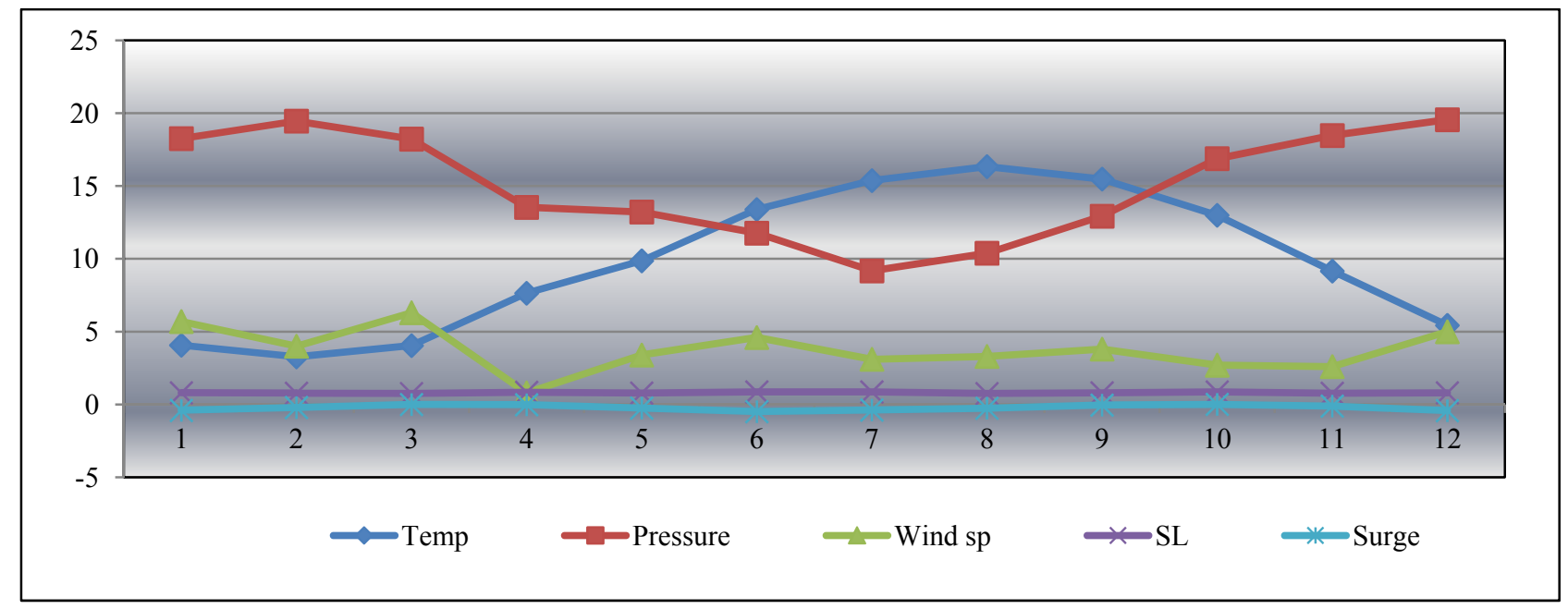

Fig. 3 The relation between air temperature, atmospheric pressure, wind speed, mean sea level and surge at Mersa Matruh during the period of the study [11]. 


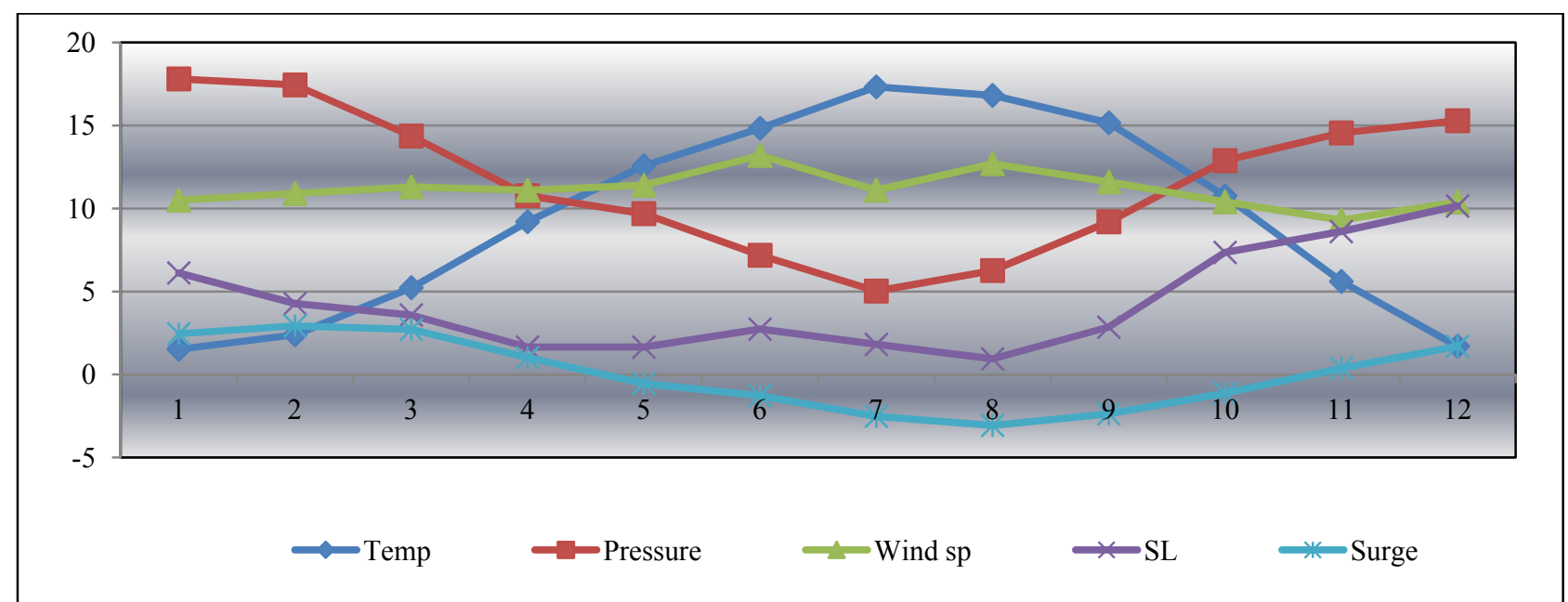

Fig. 4 The relation between air temperature, atmospheric pressure, wind speed, mean sea level and surge at Hurghada during the period of the study [11].

Table 10 The relation between the meteorological elements and the sea level (correlation coefficient) in Alexandria during (2007 to 2009) [12].

\begin{tabular}{llccc}
\hline & Temp-erature & Wind speed & Mean sea level & Surge \\
\hline Temp. & & -0.83784 & 0.86746 & 0.793879 \\
Pressure & -0.90785 & 0.647319 & -0.75668 & -0.55977 \\
\hline
\end{tabular}

Table 11 The relation between the meteorological elements and the sea level (correlation coefficient) in Port Said during (2007 to 2009) [12].

\begin{tabular}{llccc}
\hline & $\begin{array}{l}\text { Temp- } \\
\text { erature }\end{array}$ & Wind speed & Mean sea level & Surge \\
\hline Temp. & & -0.50403 & 0.781984 & 0.897681 \\
Pressure & -0.86811 & 0.151156 & -0.51857 & -0.66988 \\
\hline
\end{tabular}

Table 12 The relation between the meteorological elements and the sea level (correlation coefficient) in Mersa Matruh during (2007 to 2009) [12].

\begin{tabular}{lllll}
\hline & $\begin{array}{l}\text { Temp- } \\
\text { erature }\end{array}$ & Wind speed & Mean sea level & Surge \\
\hline Temp. & & -0.40474 & 0.359916 & -0.0244 \\
Pressure & -0.82816 & 0.381917 & -0.35686 & 0.184157 \\
\hline
\end{tabular}

Table 13 The relation between the meteorological elements and the sea level (correlation coefficient) in Hurghada during (2007-2008) [12].

\begin{tabular}{llllc}
\hline & Temp & Wind speed & Mean sea level & Surge \\
\hline Temp. & & 0.636155 & -0.68665 & -0.93729 \\
Pressure & -0.96465 & -0.66255 & 0.68576 & 0.885001 \\
\hline
\end{tabular}

\subsection{The Multiple Regression Analysis}

The multiple regression analysis was made for the four stations using STATGRAPH plus software to determine the constant factors and the relation between the dependent and independent variables.
The dependent variable is surge and the independent variables are atmospheric pressure, air temperature and wind speed. The results of fitting a multiple linear regression model are to describe the relationship between surge and the three independent variables. The equation of the fitted model is: 
Alexandria:

$$
\text { Surge }=-1918.71+2.2934 \times \text { Temp. }+1.8255 \mathrm{x}
$$$$
\text { Pressure }+2.56088 \times \text { Wind }
$$

Port Said:

Surge $=2.40126+0.69188 \times$ Temp.

$-0.0127671 \times$ Pressure $2.08985 \mathrm{x}$ Wind

Mersa Matruh:

$$
\begin{aligned}
& \text { Surge }=16.8784+0.0115497 \times \text { Temp. }+ \\
& 0.026647 \times \text { Pressure }-0.068286 \times \text { Wind }
\end{aligned}
$$

Hurghada:

$$
\begin{gathered}
\text { Surge }=426.618-2.39901 \times \text { Temp. - } \\
0.342131 \times \text { Pressure }+0.15657 \times \text { Wind }
\end{gathered}
$$

There is a statistically significant relationship between the variables at the $99 \%$ confidence level.

\section{Conclusions}

(1) Egypt's coastal areas on the Red and the Mediterranean Seas are exposed to the potential adverse effects of sea-level rise in varying amounts. The coastal Egyptian Governorates have realized the danger of these impacts on their economy and have begun positive steps towards adaptation to potential economic or social hazards;

(2) Urban expansion in coastal areas, especially in densely populated areas, poses a major threat on coastal property in that area;

(3) There is no accurate data regarding the decline of coastal lands on the Mediterranean Sea, especially in areas under extraction of oil and gas, which poses a threat on investment in those areas;

(4) Climate change poses a threat on coastal and noncoastal enterprises due to high droughts, floods and sea level rise. Egyptian authorities are taking preventive measures to reduce these risks;

(5) The Egyptian authorities also plan and implement proactively for sustainable development in threatened areas in order to preserve the right of the future generations to live safely;

(6) The Egyptian Governorates bordering the Red and the Mediterranean Seas shall take the necessary measures to adapt to future changes in the absence of potentials where decision makers make the strategic decisions regarding the development of coastal areas to adapt to possible changes.

\section{Recommendations}

(1) Develop the database for monitoring the sea level to include the Mediterranean and Red Seas, where the Egyptian authorities have a climate database for sufficient time to carry out the necessary studies;

(2) The Egyptian authorities working in the field of studying and monitoring climate change should provide the required data for studies on climate change (eg sea level, storms, salinity of water, soil, coastal temperatures, phytoplankton, pattern of erosion and information on coastal areas) for researchers to conduct studies and can therefore provide information on adaptation to future climate change;

(3) The General Authority for Remote Sensing shall provide the necessary images for study in the coastal areas to identify and assess the rates of land degradation and sea level rise;

(4) Support the researchers in the fields of sea level study, wastewater treatment and saline-contaminated plants, as well as supporting awareness programs for coastal communities and building Egyptian capacities;

(5) Studying the sea level is very important for navigation, petroleum activities, shore instructions and Suez Canal. As this research is dealing with tide, harmonic components, mean sea level, surges and their relations with the meteorological elements, it is highly recommending to continue this study depending on more data and develop a strategy for the study of changes in sea water levels;

(6) Egyptian Public Authority for Shore Protection shall review the Egyptian coastal protection projects on the Mediterranean and the Red Seas to determine whether minor or effective changes can be made after conducting the necessary studies in cooperation with the scientific authorities; 
(7) All the departments have to cooperate together in order to have a better results to help the development of the Egyptian coast;

(8) Get familiar with the new software for analysis;

(9) Follow up implemented case studies and carry out assessments and suggestions for improving and disseminating information to various concerned authorities;

(10) Establishment of an information database concerning investment in the coastal zone; Make data and information transparent to planning authorities, EIA (Environmental Impact Assessment) experts and investors.

\section{References}

[1] Sutherland, M. 2004. Sea Level Rise and Coastal Zones Managements. Lincoln Institute of Land Policy, Canada.

[2] Svensson C., and Jones, D. A. 2002. "Dependence between Extreme Sea Surge, River Flow and Precipitation in Eastern Britain.” Int. J. Climatol. 22 (10):
1149-68.

[3] Woodworth, P. L. 1987. "Trends in UK Mean Sea Level." Marine Geodesy 11 (1): 57-87.

[4] World Meteorological Organization. 1996. "Storm Surges Predication." WMO (10).

[5] Rady, A. 1979. "Variation of Sea Level at Alexandria and Its Relation to the Meteorological Conditions." M. Sc. Faculty of Science, Alexandria University.

[6] Lisitzin, E. 1974. Sea Level Changes (Vol. 8). Elsevier.

[7] Meligy, M. M. 2000. "Variation of the Different Meteorological Elements." M. Sc. Arab Academy for Science and Technology.

[8] Dawod, G., Meligy, M., and Mohamed, H. 2005. "Assessment and Modelling of Sea Level Rise and Meteorological Changes in EGYPT." In Proceedings of the Ain-Shams First International Conference on Environmental Engineering, Cairo, Egypt, April, 11-2.

[9] Heaps, N. S. 1967. "Storm Surges." Oceanogr. Mar. Biol. Rev. 5: 11-47.

[10] El Din, S. S., and Rifat, E. M. 2015. "Variation of Sea Level at Alexandria." Int. Hgd. Rev. 45 (2): 175-82.

[11] Egyptian Meteorological Authority. 2009. Marine and Weather Forecast over Eastern Mediterranean.

[12] Accessed June 13, 2017. http://www.underground.com. 